\title{
Electrical Characterization of Vacuum Thermally Deposited Aluminium Thin Film
}

\author{
${ }^{1}$ J.A. Amusan, ${ }^{2}$ A.S. Olayinka, ${ }^{1}$ Y.P. Nwambo, ${ }^{3}$ S.O. Alayande, ${ }^{2}$ O.D. Ojuh, \\ ${ }^{1}$ C.C. James, ${ }^{4}$ A. Tbiyemi, ${ }^{3}$ O.R. Adetunji, ${ }^{5}$ A.A. Fagbulu and ${ }^{3}$ W.B. Ayinde \\ ${ }^{1}$ Department of Physics and Chemical Engineering, University of Port-Harcourt, \\ P.M.B. 5323, Port-Harcourt, Rivers State, Nigeria \\ ${ }^{2}$ Department of Basic Sciences, Benson Idahosa University, P.M.B. 1100, Benin City, Nigeria \\ ${ }^{3}$ Department of Chemistry and Mechanical Engineering, University of Agriculture, \\ P.M.B. 2240, Abeokuta, Nigeria \\ ${ }^{4}$ Department of Pure and Applied Physics, Ladoke Akintola University of Technology, \\ P.M.B. 4000, Ogbomoso, Nigeria \\ ${ }^{5}$ Engineering Materials Development Institute, Akure, Nigeria
}

\begin{abstract}
Vacuum thermal evaporation technique is employed in depositing thin film of Aluminium on the microscopic glass substrate using Edward 090-10-895 B Auto 306 Vacuum Coating System. The deposition is uniform precisely between 161 and $294 \mu \mathrm{m}$ of total scan length $350 \mu \mathrm{m}$. This range is achieved through Dektak 150 Surface Stylus Profiler. The uniform deposition within this range may be attributed to strong adhesion between Aluminium film and microscopic glass substrate, proper directness of film from the source to the target in the vacuum chamber of Evaporator and pure, uncontaminated film deposition at the region. The highest Roughness, $R_{p}$ of $2700 \mathrm{~A}^{0}$ (Angstrom) is obtained between 133 and $140 \mu \mathrm{m}$ of the total scan length, $350 \mu \mathrm{m}$. The lowest roughness, $R_{v}$ of $-250 \mathrm{~A}^{0}$ which exists just at the edge of the substrate is obtained. We adopt Four-point probe collinear technique to obtain the film resistivity using Keithley, 4200 model Semiconductor Characterization System (SCS). The resistivity and conductivity values are $-4.6 \mathrm{E}-06 \Omega \mathrm{cm}$ and $-2.17391 \times 10^{5} / \Omega / \mathrm{cm}$, respectively. The conductivity value of Aluminium (Al) film as dopant can enhance the performance of the doped material and thus improve the conversion efficiency and other electrical properties of some materials used in fabricating solar cell.
\end{abstract}

Key words: Doping, vacuum deposition, thin films, microscopic glass substrate, resistivity, conductivity, solar cell

\section{INTRODUCTION}

The desire to achieve high conductive thin films from various elements or compounds suitable for application in Photovoltaic and photoconductive devices has necessitated the use of doping elements. Doping is a term used to describe the introduction of other materials (impurities called dopants) to an intrinsic (pure) semiconductor in order to achieve improved performance of the doped materials. When intrinsic semiconductor is doped with a dopant, it becomes extrinsic semiconductor. This enhances the structure and mobility of electrons required for conductivity.

Aluminium (Al) which is one of the elements of Group IIIA (others are Boron, B; Gallium, Ga; Indium, In; Thallium, TI) has been increasingly used to dope materials for effective conductivity. Al thus has three valence electrons. Being a potential donor of three electrons, it is reducing in nature and forms electrovalent bonds with other elements or compounds (Ababio, 2000).

$$
\mathrm{Al} \rightarrow \mathrm{Al}^{3+}+\mathrm{e}
$$

Recently, Aluminium is being employed in doping thin films so as to achieve highly conductive thin films and other associated improved electrical properties of the films. Thin film is a layer of material deposition whose thickness is of the order of a given wavelength of electromagnetic radiation.

The layers of materials are coated on substrates, which could be plastics, glasses or metals so as to accomplish a desirable effect. Patel (1999) defined thin film as a layer of material, typically a few micrometer $\left(\mu \mathrm{m}=10^{-6} \mathrm{~m}\right)$ or less in thickness, deposited on glass,

Corresponding Author: J.A. Amusan, Departments of Physics and Chemical Engineering, University of Port-Harcourt, P.M.B. 5323, Port-Harcourt, Rivers State, Nigeria 
stainless, steel, ceramic or other compatible substrate materials. Thin films have been noted for applications in the production of high quality camera lenses, multi-layer non-absorbing beam splitter, dichroic mirrors, photographic films, motion picture projector and astronauts' elements, photovoltaic cell, photoconductive materials, etc.

Many methods have been developed for the deposition of thin film on the substrates. The commonly used methods are Chemical Bath Deposition (CBD), Chemical Vapour Deposition (CVD), Vacuum Thermal Evaporation, Sputtering, Spray Pyrolisis, Molecular Beam Epitaxy and Electro-deposition.

The chemical bath deposition is an electroless technique that is attractive as a simple and low cost method but less effective. Vacuum thermal deposition technique is adopted for this study because of availability of Vacuum thermal evaporator its sophistication, its efficiency and uniformity in deposition of the film on the substrate.

Thin film doped with Aluminium is useful in photonic industries due to inexpensive, rich-reserve element ( $\mathrm{Al}$ ), non-toxic and better electronic matching (Lin et al., 2009). Minami et al. (2001) found the minimum resistivities and Hall mobilities of Al-doped $\mathrm{ZnO}$ and Sc-doped $\mathrm{ZnO}$. The lower resistivity obtained from Sc-doped $\mathrm{ZnO}$ is associated with their difference in Hall mobility.

Doping of $\mathrm{ZnO}$ with $\mathrm{Al}$ had been found to improve the thermal stability of resistivity of $\mathrm{ZnO}$ (Suzuki et al., 2003). Minami et al. (2001) concluded that the quaternary film co-doped Cobalt (Co), Chromium $(\mathrm{Cr})$ and vanadium, $\mathrm{V}$ with $\mathrm{Al}$ in the $\mathrm{ZnO}$ films benefits to improve the electrical conductivity.

In this research, we study and report the structure, property and electrical characteristics of Aluminium crystal thermally deposited on the microscopic glass substrate. The study reveals the potent of Aluminium as a good dopant for achieving high conductivity of thin films.

\section{MATERIALS AND METHODS}

Experimental: With the aid of laboratory tong, Al crystal is placed on the source (for direct heating by heating element, cathode) inside evaporating chamber of Edward 090-10-895B Auto 306 Vacuum Coating System (Fig. 1) immediately after the machine reaches its fine pumping stage.

Fine pumping is indicated on the touch screen panel of the Evaporator. This is achieved through the use of features like diffusion pump which trap liquid Nitrogen for fast pumping and to prevent oil contamination. Turbomolecular pump with liquid Nitrogen traps for fast

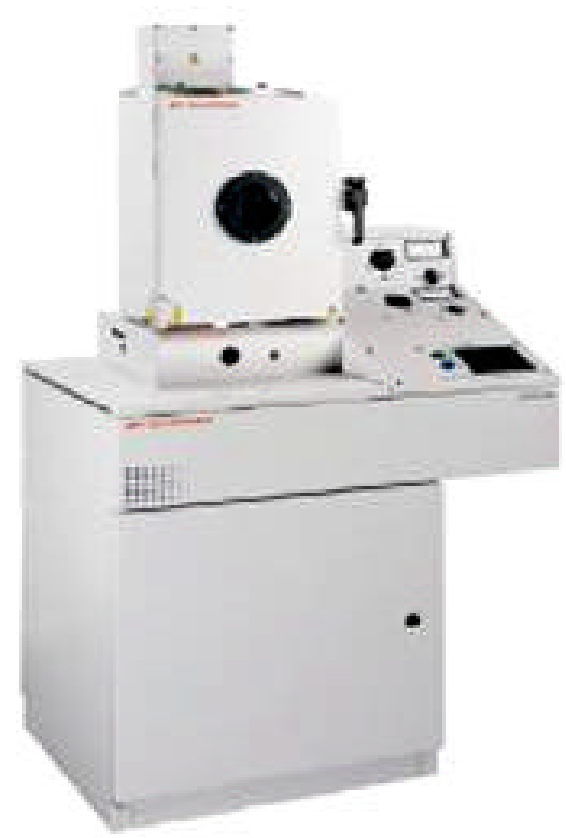

Fig. 1: A typical vacuum thermal evaporator

and clean pump down, RV 12 backing pump and water circulating chamber for efficient cycle operation of the Evaporator. The thoroughly cleaned microscopic glass slide used as substrate is placed on the sample holder in the vacuum chamber.

The $\mathrm{Al}$ film from the source is coated on the glass substrate within a short period. The thickness of deposited $\mathrm{Al}$ thin film is recorded from the screen panel. The glass substrate is removed from the vacuum chamber. A uniform, silvery, mirror-like, fine coating of Al thin film is obtained on the glass substrate.

The $\mathrm{Al}$ coated substrate is then placed on the manual $\mathrm{x}-\mathrm{y}$ sample positioning stage in Dektak 150 Surface Stylus Profiler (Fig. 2). This Surface Profiler profiles the surface topography, surface waviness and surface roughness in the nanometer range. The model, Dektak 150 is capable of measuring samples up to 6 inches in dimension, 4 inches thick, steps below $100 \mathrm{~A}^{0}$ and provides a step height repeatability of $0.6 \mathrm{~nm}\left(6 \mathrm{~A}^{0}\right)$. Thus, it enables us to study the surface roughness and waviness of $\mathrm{Al}$ film deposited on the substrate.

The electrical properties of the deposited $\mathrm{Al}$ film are then obtained through Four-Point Probe Resistivity method using Keithley Model 4200 Semiconductor Characterization System, SCS (Fig. 3). In Four-point collinear probe method, four equally spaced probes are placed in contact with the surface of materials of unknown reistance. In this case, the deposited thin film of Al. The probe array is placed in the centre of the material under 


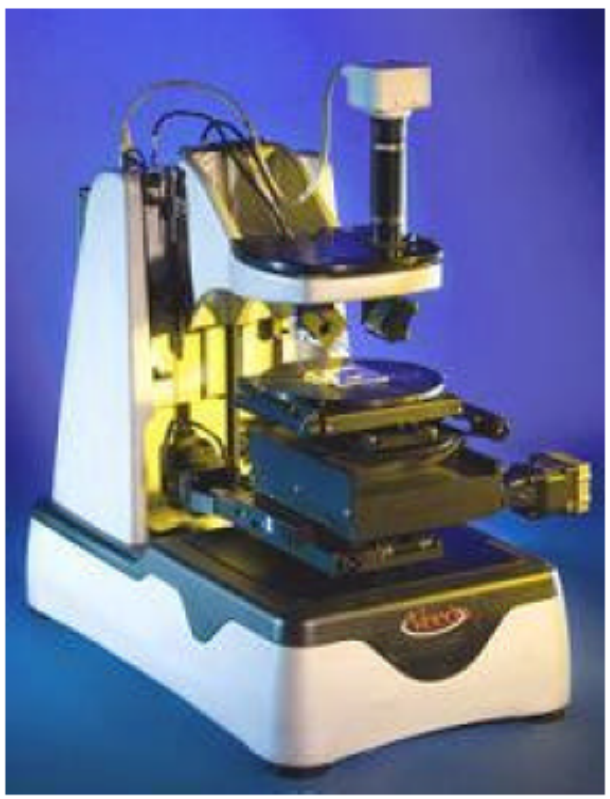

Fig. 2: A typical surface stylus profiler

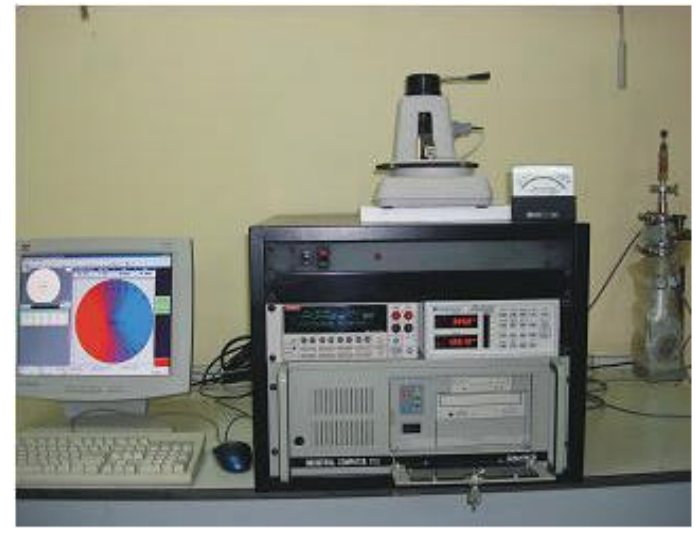

Fig. 3: A typical four-point probe system

test. The two outer probes are used for sourcing current and the two inner probes are used for measuring the resulting voltage drop across the surface of the sample. The volume resistivity of the film is calculated using:

$$
\rho=\frac{\pi}{\ln 2} \times \frac{\mathrm{V}}{\mathrm{I}} \times \mathrm{t} \times \mathrm{k}
$$

Where:

$\rho=$ Volume reietivity $(\Omega \mathrm{cm})$

$\mathrm{V}=$ The measured voltage (volts)

$I=$ The source current (Amperes)

$\mathrm{t}=$ The sample thickness $(\mathrm{cm})$

$\mathrm{K}^{*}=\mathrm{A}$ correction factor based on the ratio of the probe to wafer diameter and on the ratio of wafer thickness to probe separation
The equipment provides the wafer size, average resistance, standard deviation of resistance, average resistivity, 2-D and 3-D plots of $\mathrm{Al}$ film characteristics. This study was carried out at the Physics Advanced Laboratory of Sheda Science and Technology Complex (SHESTCO), Abuja, Nigeria in 2009.

\section{RESUL TS AND DISCUSSION}

Vacuum thermal evaporator used in this research provides improved uniform coating of $\mathrm{Al}$ thin film on the $25 \mathrm{~mm}$ microscopic glass substrate. The film of thickness $1.127 \mu \mathrm{m}$ is obtained on the substrate. The coating is mirror-like and silvery in colour.

The Surface profiler that was employed for this reseach scans with the following parameters: Stylus of radius $12.5 \mu \mathrm{m}$, Location of 11057.2 and $9209.7 \mu \mathrm{m}$, Length of scan coverage of $350.0 \mu \mathrm{m}$. Duration of scan is $15 \mathrm{sec}$, Resolution of $0.078 \mu \mathrm{m}$ sample ${ }^{-1}$, Force of $1.00 \mathrm{mg}$, Measurement range of $6.5 \mu \mathrm{m}$ and the Profile covering hills and valleys.

Figure 4 shows the surface characteristics of the film. Maximum peak of roughness, $R_{p}=2700 A^{0}$. This $R_{p}$ is obtained between 133 and $140 \mu \mathrm{m}$ of the total scan length, $350 \mu \mathrm{m}$. The lowest point of roughness, $R_{\mathrm{T}}$ is $-250 \mathrm{~A}^{0}$. This is obtained just at the beginning of the coating length. The maximum peak to valley, $R_{\mathrm{t}}$ is $2450 \mathrm{~A}^{0}$.

$$
\mathrm{R}_{\mathrm{t}}=\mathrm{R}_{\mathrm{p}}+\mathrm{R}_{\mathrm{T}}
$$

The ten-point height average, $R_{z}$-din is determined and the value is $626 \mathrm{~A}^{0}$. The $\mathrm{R}_{\mathrm{z}}$-din is given as:

$$
\mathrm{R}_{\mathrm{Z}}=\frac{1}{5}\left(\sum_{\mathrm{i}=1}^{5} \mathrm{Y}_{\mathrm{pi}}+\sum_{\mathrm{i}=1}^{5} \mathrm{Y}_{\mathrm{ri}}\right)
$$

Where:

$\mathrm{p}=$ Peak

$\mathrm{v}=$ Valley

The $R_{z}$-din measures the average height difference between the five highest peaks and five lowest valleys in accordance with DIN $4768 / 1$ specification as published by Deutsche Institute fuer Norming C.V.

Figure 4 shows highly effective uniform coating of $\mathrm{Al}$ thin film with minimum (slight) roughness between length 161 and $294 \mu \mathrm{m}$. This could be attributed to: the strong adhesion between the film and the microscopic glass substrate, proper directness of the film from the source (heated $\mathrm{Al}$ crystal) to the target (glass substrate), pure or uncontaminated film deposited within the region. The optimum performance characteristics of this $\mathrm{Al}$ thin film can thus be achieved within the range, 161 and 


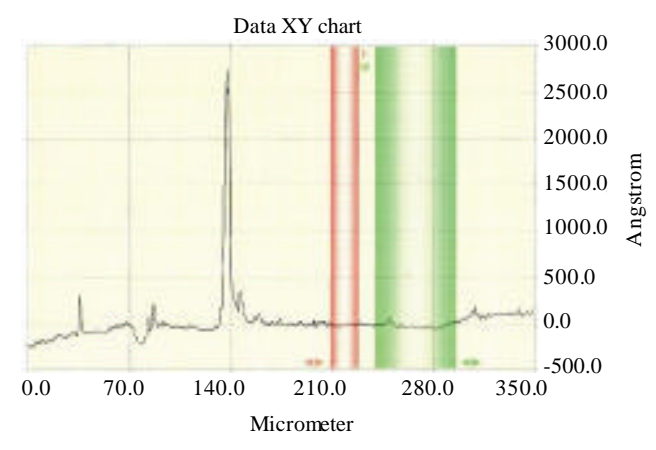

Fig. 4: Graph showing roughness of surface profile of Aluminium thin film

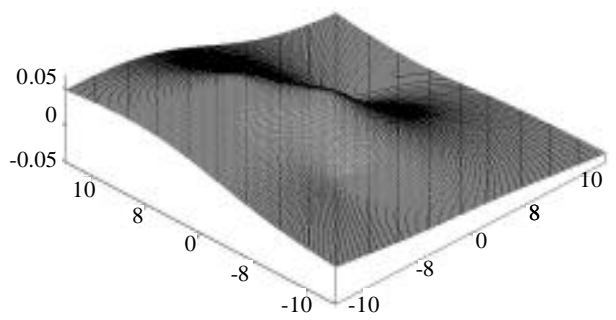

Fig. 5: Graph of 3-D average resistance

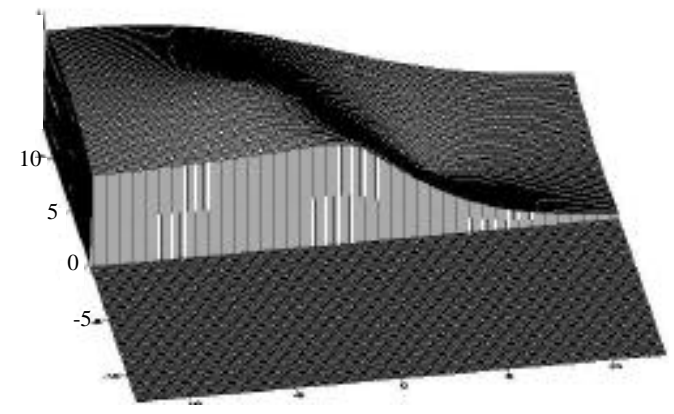

Fig. 6: Graph of half-X average resistance

$294 \mu \mathrm{m}$. Various pronounced levels of roughness are found below and beyond the range. The Keithley, 4200 model Semiconductor Characterization System (SCS) adopts Four-point probe collinear technique to provide the resistivity of the deposited Al thin film.

The following results are obtained: wafer size is $25 \mathrm{~mm}$, the current source is $4.00 \mathrm{E}-02$. The current source range determines the input impediance of the Source Meter Unit (SMU) as a voltmeter. The lower the current range is the higher the input impedance will be.

The average resistance value from various values of resistance at different probe points is 0.011798 with Standard Deviation Resistance of 4.73E-02. The average resistivity from five data points of the probe in contact with the $\mathrm{Al}$ film is determined. It is equal to $-4.6 \mathrm{E}-06 \Omega \mathrm{cm}$.

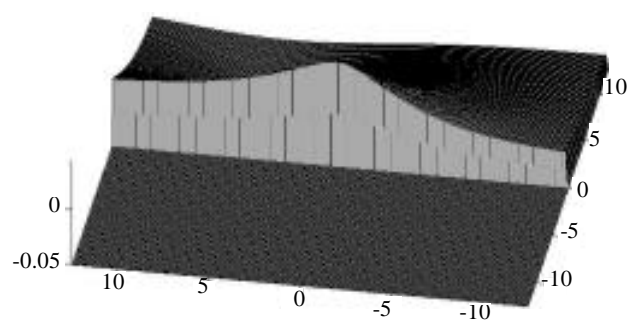

Fig. 7: Graph of half-Y average resistance

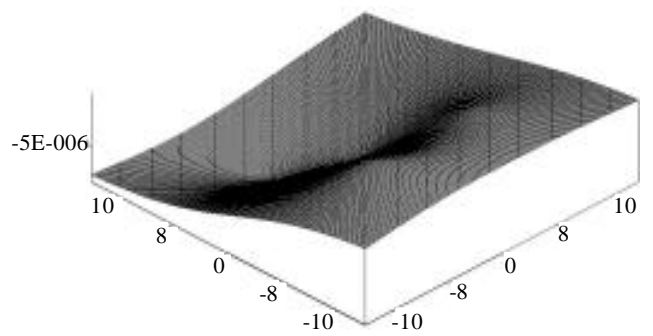

Fig. 8: Graph of 3-D average resistivity

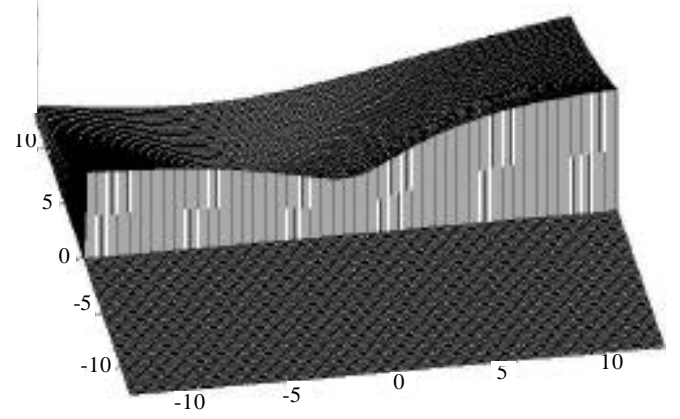

Fig. 9: Graph of half-X average resistivity

From the relation,

$$
\sigma=\frac{1}{\rho}
$$

Where:

$\sigma=$ Conductivity

$\rho=$ Resistivity

The conductivity of the film is thus inferred. Its value is $-2.17391 \times 10^{5} / \Omega / \mathrm{cm}$. The advantage of this conductivity value can be utilized to facilitate the conductivity of the doped materials for enhanced performance and improved conversion efficiency.

Figure 5-11 show 3-D graphs of Average Resistance, Half X-Average Resistance, Half Y-Average Resistance, Average Resistivity, Half X-Average Resistivity, Half $\mathrm{Y}$-Average resistivity and $\mathrm{I}-\mathrm{V}$ average, respectively. Further studies on this research will include the Hall 


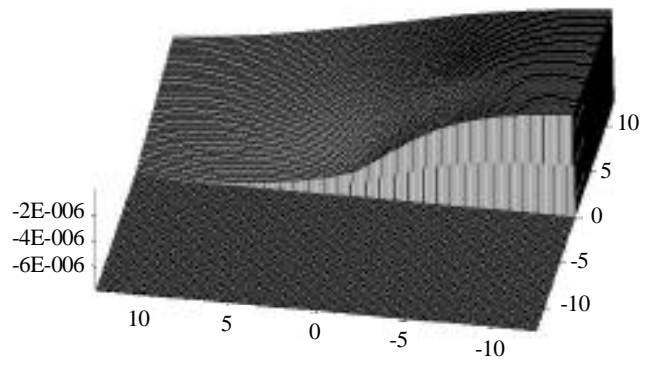

Fig. 10: Graph of half-Y average resistivity

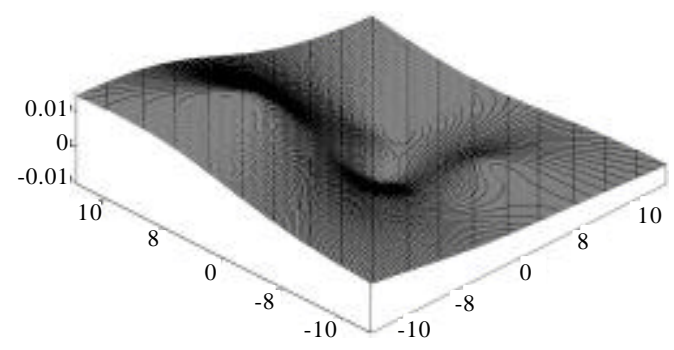

Fig. 11: Graph of 3-D average V-I

effect measurements of the film. Through Hall voltage, the conductivity type, carrier density and mobility can be derived.

\section{CONCLUSION}

Aluminium thin film has been grown on the microscopic glass substrate using the Vacuum thermal evaporator. The surface profile specifically roughness of the film formation is studied. There is specific range of length on the film which gives the uniform, uncontaminated surface film. This provides the region of optimum performance of the film. The four-point probe technique provides the resistivities at various points on the film surfaces. The average resistivity is determined to be $-4.6 \mathrm{E}-06 \Omega \mathrm{cm}$ through which the conductivity is determined to be $-2.17391 \times 10^{5} / \Omega / \mathrm{cm}$.
This electrical characteristic of Aluminium film can facilitate its use as dopant in some solar cell's film for better performance and enhanced conversion efficiency.

\section{ACKNOWLEDGEMENTS}

This study was undertaken under a programme, STEP-B project of Federal Ministry of Science and Technology and Federal Ministry of Education, Nigeria.

Special thanks to Dr A.A. Oberafor, Dr M.G. Zebaze, Mr OBI, Mr Tom and entire staff of Physics Advanced Laboratory, Sheda Science and Technology Complex (SHESTCO), Abuja, Nigeria. Also, we appreciate the support of the affiliated institutions: UNIPORT ${ }^{1}, \mathrm{BIU}^{2}$, $\mathrm{UNAAB}^{3}, \mathrm{LAUTECH}^{4}, \mathrm{EMDI}^{5}$.

\section{REFERENCES}

Ababio, O.Y., 2000. New School Chemistry. (Senior Secondary Science Series New Edition) Africana-Fep Publishers Ltd., Onitsha, Nigeria.

Lin, J.C., K.C. Peng, T.Y. Yeh and S.L. Lee, 2009. On the structure and characterization of $\mathrm{Al}, \mathrm{Sc}-\mathrm{co}$ doped $\mathrm{ZnO}$-films varying with $0-2.37$ wt. \% Sc contents. J. Thin Solid Films, 517: 4715-4719.

Minami, T., S. Suzuki and T. Miyata, 2001. Transparent conducting impurity-co-doped $\mathrm{ZnO}$ : $\mathrm{Al}$ thin films prepared by magnetron sputtering. J. Thin Solid Films, 398-399: 53-58.

Patel, R.M., 1999. Wind and Solar Power System. CRC Press, London, pp: 17-30.

Suzuki, S., T. Miyata, M. Ishii and T. Minami, 2003. Transparent Conducting V-co doped AZO thin films prepared by magnetron sputtering. J. Thin Solid Films, 434: 14-19. 